\title{
Induced liver injury after high-dose methylprednisolone in a patient with multiple sclerosis
}

\author{
Ana Torres Oliveira, ${ }^{1}$ Sandra Lopes, ${ }^{1}$ Maria Augusta Cipriano, ${ }^{2}$ Carlos Sofia ${ }^{1}$
}

${ }^{1}$ Department of

Gastroenterology, Coimbra University Hospital, Coimbra, Portugal

2Department of Pathology,

Coimbra University Hospital,

Coimbra, Portugal

\section{Correspondence to}

Dr Ana Torres Oliveira,

torresoliveiraana@gmail.com

Accepted 8 July 2015

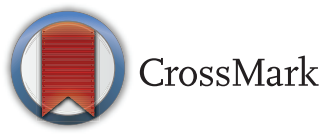

To cite: Oliveira AT, Lopes S, Cipriano MA, et al. BMJ Case Rep Published online: [please include Day Month Year] doi:10.1136/ bcr-2015-210722

\begin{abstract}
SUMMARY
A 33-year-old woman with multiple sclerosis, medicated with high doses of methylprednisolone, cyclophosphamide and glatiramer acetate, was referred to our department due to acute liver injury. The laboratory investigation was normal except for weakly positive antinuclear antibodies. Cyclophosphamide and glatiramer acetate were suspended, and intravenous immunoglobulin with maintenance of high doses of methylprednisolone was initiated. The patient developed another episode of acute hepatitis so the immunoglobulin was stopped. After that, she had three more episodes of elevation of liver enzymes with no hepatic insufficiency while medicated only with high doses of methylprednisolone. At this time, liver biopsy showed focal centrilobubar hepatocyte necrosis with minimal interface hepatitis. After the high doses of methylprednisolone were suspended, the patient remained asymptomatic, with normal hepatic enzymes. This case emphasises that, although rare, induced liver injury after high doses of methylprednisolone can occur.
\end{abstract}

\section{BACKGROUND}

Drug-induced liver injury (DILI) is an important cause of acute liver failure with an estimated incidence of 1-10 000 to $1-100000$ treated patients. ${ }^{12}$ The clinical manifestation may vary from transitory mild elevation of liver enzymes to fulminant liver failure and death. ${ }^{3}$ Multiple sclerosis (MS) is a chronic recurrent autoimmune disease of the central nervous system, of unknown aetiology. High doses of intravenous methylprednisolone are useful for its treatment and are also used in the treatment of other autoimmune disorders and even in acute hepatitis. ${ }^{4}$ Although severe liver injury is not mentioned among the possible side effects of methylprednisolone, acute and serious liver injury induced by corticosteroids can occur. It is extremely rare with only a few cases described in the literature. ${ }^{5}$

\section{CASE PRESENTATION}

A 33-year-old woman with a diagnosis of severe MS 9 months prior, was referred to our hospital with jaundice that evolved over 4 days, with no other associated signs or symptoms. In the last sixth months, she had been treated for her MS with cyclophosphamide and glatiramer acetate. She had also been treated with high doses of methylprednisolone $1 \mathrm{~g} /$ day, with oral maintenance because of the severity of the disease. No ethanol consumption, no toxic exposition and no other medications were reported. Laboratory analysis showed total bilirubin of $16 \mathrm{mg} / \mathrm{dL}$ (normal $0.3-1.2 \mathrm{mg} / \mathrm{dL}$ ), direct bilirubin $9.7 \mathrm{mg} / \mathrm{dL}$ (normal $0.1-0.5 \mathrm{mg} / \mathrm{dL}$ ), aspartate aminotransferase (AST) $710 \mathrm{U} / \mathrm{L}$ (normal $<35 \mathrm{U} / \mathrm{L}$ ), alanine aminotransferase (ALT) $2308 \mathrm{U} / \mathrm{L}$ (normal $<45 \mathrm{U} / \mathrm{L}$ ), $\gamma$-glutamyl transferase (GGT) $247 \mathrm{U} / \mathrm{L}$ (normal $<55 \mathrm{U} / \mathrm{L}$ ), phosphatase alkaline $92 \mathrm{U} / \mathrm{L}$ (normal 40-150 U/L), prothrombin index $36 \%$, factor $\mathrm{V} 76 \%$ and factor VII 17\%. Virology for hepatitis B, C and A, herpes simplex virus, Epstein-Barr virus and cytomegalovirus were negative. Serum immunoglobulins were normal and all autoimmunity markers were negative, except for antinuclear antibodies, which were weakly positive (titre of $1: 40$ ), with a fine dense granular pattern. Serum ceruloplasmin, ferritin, transferrin saturation and $\alpha 1$ antitrypsin were negative. The lymphocyte transformation test was negative for cyclophosphamide and glatiramer acetate. Abdominal ultrasound with liver and spleen evaluation was normal. During hospitalisation, all the patient's medications were suspended and she received supportive therapy only. She gradually recovered with analytical improvement on liver enzymes: total bilirubin $2.6 \mathrm{mg} / \mathrm{dL}$, AST $117 \mathrm{U} / \mathrm{L}$, ALT $275 \mathrm{U} / \mathrm{L}$, GGT $115 \mathrm{U} / \mathrm{L}$ and phosphatase alkaline $51 \mathrm{U} / \mathrm{L}$. She was discharged with suspension of cyclophosphamide and glatiramer, but she was maintained on high doses of methylprednisolone and started on human normal intravenous immunoglobulin G (IVIG). After 9 months, she once again developed acute hepatitis with hepatic insufficiency. The analytical and imagiological studies were negative and the antinuclear antibodies remained positive with the same titre. A liver biopsy was performed, which showed severe interface hepatitis, and centrilobular hepatocyte necrosis and mild fibrosis, suggesting an autoimmune or drug-induced liver injury aetiology. At this time, the patient suspended all medication (including IVIG) except the high doses of methylprednisolone, and over the following year she developed three more episodes of elevation of liver enzymes (ALT and AST over five times the upper normal limit), but with no hepatic insufficiency. When she was receiving only high doses of methylprednisolone, the liver biopsy was repeated, showing a focal centrilobubar hepatocyte necrosis with minimal interface hepatitis and no fibrosis. After a multidisciplinary discussion, it was decided to suspend the high doses of methylprednisolone and initiate natalizumab. 


\section{OUTCOME AND FOLLOW-UP}

After stopping the high doses of methylprednisolone and starting natalizumab, and after 1 year of follow-up, the patient remains asymptomatic with normal liver enzymes.

\section{DISCUSSION}

We present a case of severe liver injury induced by high doses of methylprednisolone in a patient with MS. The diagnosis was established by excluding other causes and other medications, and by the relationship between drug administration/hepatic injury and normalisation of liver enzymes after the suspension of methylprednisolone. In the initial episodes, we could not exclude the fact that the other medications might also have contributed to liver damage, however, we were able to assume the normalisation of liver tests after methylprednisolone withdrawal as a positive dechallenge. Liver dysfunction can occur in patients with MS, but most times it is related to drug toxicity. On review of the literature, few cases of liver injury induced by corticosteroids were found. ${ }^{5}{ }^{6}$ Besides being a rare condition, it has also been under-reported. The clinical presentation varies from subtle elevation of liver enzymes to fulminant hepatitis. Also, the characteristic features on histological examination exhibit a variety of patterns such as steatohepatitis, interface hepatitis and bridging necrosis. 57

DILI is uncommon but it represents the most frequent cause for drug withdrawal after initial approval and is an important reason for liver transplant. ${ }^{8}$ The mechanism of toxicity is predominantly idiosyncratic, meaning liver injury is unexpected, and it depends on individual susceptibility related to risk factors and genetic polymorphisms. Idiosyncratic lesions can be divided into immunoallergic and metabolic (non-allergic). The immunoallergic reaction occurs due to the interaction of the drug or its metabolites with cells of the immune system, leading to necrosis and apoptosis of hepatocytes. It can be associated with symptoms of hypersensitivity (eg, rash, fever, joint pain). The metabolic reaction occurs because of an aberrant metabolism of the drug leading to local accumulation of toxic metabolites, subsequent oxidative stress and cell necrosis. ${ }^{9} 10$ The exact mechanism responsible for hepatic injury related to methylprednisolone is unknown. Some authors relate the injury with reactivation of $\mathrm{HBV}$ infection and others relate it to drug-induced injury linked to the medication excipient. ${ }^{5}$ It is also supposed to be related to the decrease of nuclear factor- $\kappa \mathrm{B}$ activity, where activation leads to tumor necrosis factor- $\alpha$ production that has a protective effect on the liver. ${ }^{11}$ In cases of chronic use of low doses of methylprednisolone, steatosis and steatohepatitis can occur leading to subtle changes in liver enzymes. In patients with autoimmune diseases, such as MS, concomitant autoimmune hepatitis (AIH) should always be considered since the prevalence of $\mathrm{AIH}$ is $0.017 \%$ in the general population and it can be 10 times higher in patients with MS. ${ }^{12}$ Distinguishing immune-mediated DILI from AIH is difficult since the clinical presentation can be similar and the histological pattern such as centrilobular necrosis is not helpful in distinguishing the two entities. ${ }^{13} \mathrm{AIH}$ a chronic, immunologically mediated inflammation of the liver. The aetiology is uncertain but the disease can be triggered in genetically predisposed persons by environmental factors such as viruses, drugs and herbs. In a report on patients with classical features of $\mathrm{AIH}$, about 9\% were drug induced and most of the cases (90\%) were associated with minocycline and nitrofurantoin. ${ }^{14}$

In our case, applying the simplified diagnostic criteria for $\mathrm{AIH}$ was neither compatible nor probable for the disease. The histological pattern with focal centrilobular necrosis and liver enzyme normalisation after the discontinuation of the methylprednisolone was in favour of an immune-induced drug liver injury. Nevertheless, this histological pattern can also be found in the initial forms of AIH and so, although less probable, we could not exclude drug-induced AIH.

In conclusion, DILI caused by high doses of methylprednisolone is rare and the mechanism in not exactly known. In patients with other autoimmune diseases, such as MS, the diagnosis is difficult to establish because immune mediated liver toxicity and AIH have the same immunological background, and therefore show the same clinical and histopathological features.

\section{Learning points}

- Induced liver injury after high doses of methylprednisolone is rare.

- The mechanism of injury is unknown but it seems to be immune mediated.

- Drug-induced liver injury and autoimmune hepatitis may be difficult to differentiate, because of the similar clinical and histopathological features.

- Patients with multiple sclerosis taking high doses of methylprednisolone should be monitored.

Contributors ATO selected the clinical data and wrote the manuscript. MAC performed the histopathological evaluation of the liver biopsy. SL and CS participated on the literature review and in revising the manuscript.

Competing interests None declared.

Patient consent Obtained.

Provenance and peer review Not commissioned; externally peer reviewed.

\section{REFERENCES}

1 Stirnimann G, Kessebohm K, Lauterburg B. Liver injury caused by drugs: an update. Swiss Med Wkly 2010;140:w1308.

2 Bjornsson E. Review article: drug-induced liver injury in clinical practice. Aliment Pharmacol Ther 2010;32:3-13.

3 Kazuto T, Yukihiro S. Practical guidelines for diagnosis and early management of drug-induced liver injury. World J Gastroenterol 2008;14:6774-85.

4 Goodin DS, Frohman EM, Garmany GP, et al., Therapeutics and Technology Assessment Subcommittee of the American Academy of Neurology and the MS Council for Clinical Practice Guidelines. Disease modifying therapies in multiple sclerosis: report of the Therapeutics and Technology Assessment Subcommittee of the American Academy of Neurology and the MS Council for Clinical Practice Guidelines. Neurology 2002;58:169-78.

5 Gutkowski K, Chwist A, Hartleb M. Liver injury induced by high-dose methylprednisolone therapy: a case report and brief review of the literature. Hepat Mon 2011;11:656-61.

6 D'Agnolo H, Drenth J. High-dose methylprednisolone-induced hepatitis in a patient with multiple sclerosis: a case report and brief review of literature. Neth J Med 2013:71:199-202.

7 Melamud B, Yoav L, Levi I, et al. Methylprednisolone-induced liver injury: a diagnostic challenge. Isr Med Assoc J 2014;16:180-1.

8 Chalasani N, Fontana RJ, Bonkovsky HL, et al., Drug Induced Liver Injury Network (DILIN). Causes, clinical features, and outcomes from a prospective study of drug-induced liver injury in the United States. Gastroenterology 2008;135:1924-34.

9 Holt MP, Ju C. Mechanisms of drug-induced liver injury. AAPS J 2006;8:48-54.

10 Chen M, Suzuki A, Borlak J, et al. Drug-Induced liver injury: interactions between drug properties and host factors. J Hepatol 2015;50168-8278:00299-8.

11 Eggert M, Goertsches R, Seeck U, et al. Changes in the activation level of NF-kappa $\mathrm{B}$ in lymphocytes of MS patients during glucocorticoid pulse therapy. I Neurol Sci 2008:264:145-50.

12 Reuss R, Retzlaff K, Vogel $S$, et al. Autoimmune hepatitis after high-dose intravenous methylprednisolone pulse in RR-MS. CEJMed 2007;2:356-9.

13 Weiler-Normann C, Schramm C. Drug induced liver injury and its relationship to autoimmune hepatitis. J Hepatol 2011;55:747-9.

14 Bjornsson E, Talwalkar J, Treeprasertsuk S, et al. Drug-induced autoimmune hepatitis: clinical characteristics and prognosis. Hepatology 2010;51:2040-8. 
Copyright 2015 BMJ Publishing Group. All rights reserved. For permission to reuse any of this content visit http://group.bmj.com/group/rights-licensing/permissions.

BMJ Case Report Fellows may re-use this article for personal use and teaching without any further permission.

Become a Fellow of BMJ Case Reports today and you can:

- Submit as many cases as you like

- Enjoy fast sympathetic peer review and rapid publication of accepted articles

- Access all the published articles

- Re-use any of the published material for personal use and teaching without further permission

For information on Institutional Fellowships contact consortiasales@bmjgroup.com

Visit casereports.bmj.com for more articles like this and to become a Fellow 